\title{
Investigating the impact of inoculum source on anaerobic digestion of various species of marine macroalgae
}

Oluwatosin Obata

Arlene Ditchfield

Angela Hatton

Joseph Akunna

This is the accepted manuscript (C) 2020, Elsevier Licensed under the Creative Commons AttributionNonCommercial-NoDerivatives 4.0 International: http://creativecommons.org/licenses/by-nc-nd/4.0/

The published article is available from doi: https://doi.org/10.1016/j.algal.2020.101803 


\title{
Investigating the impact of inoculum source on anaerobic digestion of various species of marine macroalgae
}

\author{
Oluwatosin Obata ${ }^{a^{*}}$, Arlene Ditchfield ${ }^{a}$ Angela Hatton ${ }^{a}$ and Joseph Akunna ${ }^{b}$ \\ aScottish Association for Marine Science, Dunstaffnage Laboratory, Oban. PA37 1QA, \\ UK. \\ bUrban Water Technology Centre, School of Science, Engineering and Technology, \\ Abertay University, Bell Street, Dundee DD1 1HG, UK. \\ ${ }^{*}$ Corresponding author E-mail: oluwatosin.obata@ncl.ac.uk; Tel: +44(0)7528020401.
}

\begin{abstract}
This study investigated the intrinsic biodegradation potential of marine organic sediment for effective biogas production from various species of marine macroalgae and nonmarine biomass. Biogas production potential tests were carried out on three species of seaweed harvested from the west coasts of Scotland, Laminaria digitata, Fucus serratus, and Saccharina latissima, and on a non-marine cellulose biomass seeded with uncultivated and unadapted anoxic marine sediments. As a comparison, the same experiments were repeated using the same substrates but seeded with active mesophilic anaerobically digested sewage sludge. For the cultures seeded with anoxic marine sediments, the highest methane yield was observed in both $L$. digitata and $S$. latissima cultures while $F$. serratus and cellulose, cultures performed relatively poorly. For those seeded with digested sludge, all cultures performed relatively well, except $F$. serratus. These results show that marine sediments can be effective inoculum for seaweeds digestion. Phylogenetic analyses of the methanogenic community in both sources of inoculum showed that the methanogen community within the sediment and sludge seeded cultures were different. Each culture was dominated by methanogenic populations suitable for the utilization of the specific biomass derivatives and environmental conditions. For instance, members of the genus Methanosaeta which, dominated sludge seeded cultures were not detected in the sediment seeded cultures. A similar occurrence was observed for the genus Methanofolis which was only detected in the sediment seeded cultures. Hence, in areas where seaweed forms part of a codigestion with non-marine biomass, start-up using a mixture of anoxic marine sediments and digested wastewater sludge has the potential to provide greater process stability and robustness than using either as sole inoculum.
\end{abstract}

Keywords: anaerobically digested sewage sludge inoculum, marine macroalgae species, marine sediments inoculum; methanogenic microbial community; seaweeds 


\section{Introduction}

The current global quest for alternative, sustainable and renewable energy has renewed interests in a number of possible sources of renewable energy [1,2]. Bioenergy appears to be a viable option because it can be sourced locally and it is one

of the very few forms of renewable energy that can be stored [1-3]. Of all the alternative energy sources currently considered, biomass represents the most ready to be utilised on a large scale with minimal environmental and economic implications [4]. However, there are concerns about growing terrestrial crops ( $1^{\text {st }}$ generation biofuels) for bioenergy production which may make negligible contribution to net greenhouse gas emission and cause other problems relating to water and food shortages [5-7]. Therefore, the current quest for increased utilisation of seaweeds $\left(3^{\text {rd }}\right.$ generation biofuels) as a potential resource for renewable energy production is timely. Marine biomass, such as seaweed, offers an attractive option for producing renewable energy in a more sustainable manner [7-10].

Apart from its ability to efficiently fix $\mathrm{CO}_{2}$ faster than most terrestrial plants [12], seaweeds have a number of advantages over terrestrial biomass as source of renewable energy. These include, lack of lignin, which makes up a bulk of terrestrial biomass, thereby making it relatively easier material for bioconversion, and its cultivation does not require arable land or fresh water, therefore there is no competition with food crops $[7,9,10]$. Nevertheless, the presence of salt and polyphenols in seaweeds can inhibit microbial biodegradation, as a result, dilution of the feedstock has been proposed as a means of ensuring efficient biodegradation [9]. However, dilution requires the use of freshwater and undermines the sustainability of the process. It is therefore pertinent to seek ways to ensure effective biodegradation without a need for freshwater dilution. 
The type of inocula utilised for start-up of anaerobic digestion of biomass is one of the important factors that determine the eventual composition of the microbial community and hence efficiency of the process [11,12]. Different sources of inoculum have been used for the anaerobic digestion of seaweeds by many researchers in an attempt to quicken process start-up through faster acclimatisation to the type of feedstock and environmental conditions such as high salinity levels, and thus enhance methane yield. Non-marine sourced anaerobic sludge appears to be the dominant source of inoculum for the start-up of biomethanation of seaweeds as reported in the literature. For instance, Chynoweth, et al.,[13] seeded L. digitata with anaerobically digested mesophilic sludge in a conventional reactor operating at mesophilic temperature and reported maximum methane production of $280 \mathrm{ml} / \mathrm{g}$ VS added after 30 days. Thermophilic digestion of S. latissima seeded with sludge obtained from cultures treating cattle manure operating under thermophilic conditions $\left(55^{\circ} \mathrm{C}\right)$ reported a maximum methane production of $340 \mathrm{ml} / \mathrm{g} \vee S_{\text {added }}$ after 34 days of operation [14]. Similarly, a biochemical methane potential (BMP) test of Ulva lactuca using inoculum effluent from cattle manure thermophilic digester in a reactor operated at $52^{\circ} \mathrm{C}$ produced $271 \mathrm{ml} / \mathrm{g} \mathrm{VS}$ added after 42 days of incubation [5]. However, in areas where there is no accessible anaerobic digestion plant to obtain seed sludge, such as in remote sparsely populated coastal locations with abundant supply of seaweeds, the start-up or re-start of seaweed anaerobic digestion plant will pose a substantial challenge. Recent research by Miura et al., 2014 [15] and Miura et al., 2015 [16], found the use of anoxic sediments as inoculum for seaweed anaerobic digestion to be promising. However, these studies involved serial cultivation of the sediment inoculum in order to ensure effective adaptation to the salinity conditions of seaweeds prior to its use as inoculum, thereby making the process time consuming and involving a great amount of material and human resources. Furthermore, the study used only one species of seaweed, $S$. 
japonica. Since many previous studies $[17,18]$ have shown that various species respond differently to anaerobic biodegradation, it is not clear if the type of seaweed can affect the effectiveness of sediment inoculum. Hence, to investigate the effectiveness of marine sediments as inoculum for anaerobic digestion operations in rural coastal communities, it is important to evaluate its performance using different species of seaweed. Such seaweeds, which have not been washed with freshwater to reduce their salinity contents would be utilised and compared with the same seaweed cultures seeded with anaerobic activated sewage sludge, a commonly used source of inoculum. Thus, the objectives of this study are to:

- Access the suitability of anoxic sediment as a source of inoculum for anaerobic digestion of seaweeds

- Evaluate and compare the effect of inoculum source fate of the methanogenic community present in the different seaweed cultures.

\section{Materials and methods}

\subsection{Substrates (Seaweeds)}

Fresh seaweeds, Laminaria digitata, Fucus serattus and Sacharrina Latissima, were harvested from the beach near Scottish Association for Marine Science, (SAMS) near Oban (56 $\left.27^{\prime} 09.5^{\prime \prime} \mathrm{N} 5^{\circ} 26^{\prime} 43.2^{\prime \prime} \mathrm{W}\right)$ in August, 2012 at low tide. These species ( $L$. digitata, F. serattus and S. latissima) were selected based on three key considerations, availability, carbohydrate content [7,19], and potential for large scale cultivation [20]. The seaweeds were transferred within an hour to the lab, frozen overnight, freeze-dried and manually grinded using ceramic mortar and pestle to powder and sieved $<1 \mathrm{~mm}$. Powdered seaweeds were stored in sealed plastic bags at room temperature until use. 
Cellulose powder (Fluka, Sigma-Aldrich, Denmark) was used as the positive control [21] for comparison with the biodegradation of the seaweeds.

\subsection{Seed inocula}

The first seed inoculum was anaerobic digested sludge obtained from Hatton municipal wastewater treatment plant near Dundee (Scotland) operating at mesophilic temperature of about $37^{\circ} \mathrm{C}$. The second inoculum was anoxic surface sediments, obtained in the vicinity of a fish farm (sediment exposed to organic input) from Loch Linnhe, $\left(56^{\circ} 35^{\prime} 31.5^{\prime \prime} \mathrm{N} 5^{\circ} 22^{\prime} 44.3^{\prime \prime} \mathrm{W}\right)$.It was transported in a closed container to avoid exposure to oxygen and transferred to the lab within 5 hours of collection. In the lab, the sediment was homogenised using mechanical stirrer and was diluted using sterile water to achieve the desired volatile solids content and immediately put under anaerobic condition. The choice of location for sediments was to ensure a greater diversity of microbes for a range of seaweeds species. Both inocula were incubated at $37^{\circ} \mathrm{C}$ for 24 hours before use. The characteristics of experimental materials are shown in Table 1.

Table 1: Characterisation of experimental materials

\begin{tabular}{llllll}
\hline Component & L. digitata* $^{*}$ & F. serattus & S. latissima* & $\begin{array}{l}\text { Anoxic } \\
\text { Sediment }\end{array}$ & $\begin{array}{l}\text { Digested } \\
\text { sludge }\end{array}$ \\
\hline TS (wet \%) & $27 \pm 1.4$ & $29 \pm 0.9$ & $27.5 \pm 1.32$ & $97.7 \pm 2.2$ & $22.9 \pm 1.2$ \\
VS (dry \%) & $85.41 \pm 3$ & $81.14 \pm 2.1$ & $87.64 \pm 2.30$ & $18.56 \pm 1.8$ & $13.19 \pm 0.8$ \\
Ash (dry \%) & $14.59 \pm 1.4$ & $18.86 \pm 1.6$ & $12.36 \pm .1 .3$ & $79.14 \pm 2.4$ & $30.8 \pm 1.4$
\end{tabular}

Results are represented by an average of 3 replicates $\pm S D$

*Detailed characterization of the algal biomass is described by Schiener at al, 2014

\subsection{Buffer solution}

A synthetic mineral buffer was used to provide essential nutrients and stabilise the $\mathrm{pH}$. The composition of the buffer [22], include; $2.7 \mathrm{~g} / \mathrm{L} \mathrm{KH}_{2} \mathrm{PO}_{4}$ (strong buffer agent), 3.5 g/L K ${ }_{2} \mathrm{HPO}_{4}$ (strong buffer agent), $5 \mathrm{mg} / \mathrm{LMgSO}_{4} .7 \mathrm{H}_{2} 0,0.5 \mathrm{mg} / \mathrm{LCaCl}_{2}, 0.5 \mathrm{mg} / \mathrm{LFeCl}_{3}$, $0.5 \mathrm{mg} / \mathrm{LKCl}_{3}, 0.1 \mathrm{mg} / \mathrm{LCoCl}_{2}$ and $0.1 \mathrm{mg} / \mathrm{LNiCl}_{2}$ in seawater. Seaweeds contain 
sufficient phosphorus and source of nitrogen to support the growth of microorganisms during anaerobic digestion [20].

\subsection{Experimental Design}

To maintain adequate mass transfer balance, $5 \mathrm{~g}$ of substrates (seaweeds and cellulose) in $150 \mathrm{ml}$ of non-growth medium was placed into $575 \mathrm{ml}$ capacity test bottles and seeded with $150 \mathrm{ml}$ of anoxic sediment or digested sludge. The mixtures were set up to a working volume of $300 \mathrm{ml}$ leaving a $275 \mathrm{ml}$ headspace for gas measurement. Each culture composed of substrates to inoculum ratio (VS:VS) of $1: 1$, as recommended in the literature [21].

After set-up, the $\mathrm{pH}$ values of the cultures were adjusted to $7.5 \pm 0.3$, and the bottles sealed with septum and tightly closed with aluminium caps. The headspaces were thereafter flushed with nitrogen at $0.1 \mathrm{dm}^{3} \mathrm{~min}^{-1}$ for 2 minutes and sealed with silicon sealant (SwiftSeal ${ }^{\circledR}$ UK).

The blanks (negative controls) containing only inoculum and buffer solution were included to account for any methane produced due to residual substrates in the inocula. All cultures were performed in triplicates and incubated at $37^{\circ} \mathrm{C}$ for 50 days.

\subsection{Sampling}

Gas composition was analysed from the headspace using $100 \mu \mathrm{l}$ gas tight syringes daily in the first 10 days and at 3days interval afterwards, while gas volume was determined using syringes. To ensure that the residual pressure was negligible, the size of syringes used changed between $50 \mathrm{ml}$ to $1 \mathrm{ml}$. Samples for microbial analyses were collected after thorough homogenisation of the batch reactor by using needles with larger pores, sealed with silicon material (SwiftSeal ${ }^{\circledR}$ UK) and checked with water to ensure no leakages. Syringes (with $\sim 1 \mathrm{~mm}$ needles) were used to draw samples for 
microbial analyses in other to avoid opening the cultures. Gas volume measurements took into account changes in headspace volume over time. Methane concentration (\%) was multiplied by the increasing volume of the batch headspace to account for the cumulative increases in headspace volume over time.

\subsection{Analytical Methods}

Headspace methane concentration was analysed daily in the first 10 days of the experiment and every 3 days afterwards using Gas Chromatography (HEWLETT PACKARD 5890 SERIES 11, USA) previously described [21]. Total solids and moisture content of the seaweeds and seed inoculums were determined according to standard procedures [20] in triplicates. The volatile fatty acids (VFAs) concentration was determined by esterification method [23], while colorimetric determination was done using a $\mathrm{HACH} \mathrm{DR} / 5000$ (HACH method 8196). The $\mathrm{pH}$ was measured using $\mathrm{pH}$ meter Senslon $3(\mathrm{HACH})$ at regular intervals as indicated above.

\subsection{Molecular techniques}

DNA was extracted from the seaweeds cultures $(0.5 \mathrm{~mL}$; from both the sludge and sediment seeded cultures) in duplicate on Day 20 (a period of considerable methane production) of the anaerobic digestion process using the FastDNA spin kit for soils (MP Biomedical, USA) according to manufacturer instructions. Extracted DNA was quantified using a spectrophotometer (Thermo Scientific ${ }^{\text {TM }}$ Evolution $^{\text {TM }} 260$ Bio spectrophotometer, USA) and were diluted 1/10 to achieve optimal concentration for PCR. Methanogens were detected by targeting the $\alpha$-subunit of the methyl-coenzyme $M$ reductase $(m r c A)$ gene which encodes the enzyme catalysing the last step in methanogenesis and is found in all known methanogens [24]. For specific methanogens studies, primer pair targeting the mcrA gene: mlas 
(5'-GGTGGTGTMGGDTTCACMCARTA-3') and m-rev (5'-

CGTTCATBGCGTAGTTVGGRTAGT-3') which produces 500bp DNA fragment were employed as previously described [24]. All PCR runs were carried out in a total $25 \mu \mathrm{l}$ volume containing $0.5 \mu \mathrm{l}$ of forward primer, $0.5 \mu \mathrm{l}$ of reverse primer (10pmoles/ $\mu \mathrm{l})$, and $0.1 \mu \mathrm{l}$ of MyTaq polymerase $(5 \mathrm{u} / \mu \mathrm{l})$. Other components of the mix are $5 \mu \mathrm{l}$ of PCR Buffer (comprising $5 \mathrm{mM}$ dNTPs, $15 \mathrm{mM} \mathrm{MgCl}_{2}$, stabilizers and enhancers), $18.4 \mu \mathrm{l}$ of molecular grade water $(17.4 \mu \mathrm{l})$ and $0.5 \mu \mathrm{l}$ of DNA extract. Negative controls containing $0.5 \mu \mathrm{l}$ of sterile molecular grade water were included in all cases. All primers were obtained from Integrated DNA Technologies, (Belgium) while other reagents were obtained from Bioline Reagents Ltd, (London, UK). Duplicate PCR products were pooled and purified with the QiaQuick PCR Purification Kit (Qiagen, USA) prior to being used in the cloning reaction [25].

Clone libraries were constructed by ligating the mcrA gene PCR products into pCR 2.1TOPO® vector and transformed into One Shot TOP10 chemically competent Escherichia coli using the TOPO TA® cloning kit according to the manufacturer's instructions (Invitrogen, CA, USA).

Transformed clones were screened using LB plates containing Ampicillin $(50 \mathrm{mg} / \mathrm{ml})$ [26]. Randomly selected colonies were re-streaked onto new LB plates overnight at $37^{\circ} \mathrm{C}$. Selected clones were used directly in PCR reactions using vector-specific primers M13F (5'-TGTAAAACGACGGCCAGT - 3') and M13R (5'CAGGAAACAGCTATGACC -3') (Invitrogen) as previously described $[27,28]$. PCR product $(5 \mu \mathrm{l})$ were visualised by agarose gel electrophoresis to check the sequences were the right sizes. Clones (56) of the correct size were purified (QIAquick spin columns, Qiagen, Crawley, UK) and sequenced using the primer M13F by Source Bioscience (Glasgow, UK) using Sanger Sequencing approach. Sequences were 
viewed and corrected using FinchTV Version 1.4.0 (Geospiza Inc.) and aligned using Bioedit Sequence Alignment Editor. Nucleotide sequences from the clone library and were compared to the GenBank database using FASTA [29]. The acceptable percentage of identity was set at $\geq 70 \%$ (for $m c r A$ gene fragments) and minimum nucleotide length was 196bp [30].

\subsection{Statistical analysis}

Experimental error was determined for replicate assays and expressed in standard deviation. The significances of differences in results were determined by one-way analysis of variance (ANOVA). Statistical significant interactions were further analysed using post hoc test (Tukey) at $95 \%$ confidence interval. Differences between species and across treatments were also determined. All statistical analyses were performed using Minitab Statistical Software (Pen. State University, USA) version 17.0. 


\section{Results and discussion}

During the 50-day test, $\mathrm{pH}$, VFAs and methane production were measured as a function of process performance. The results as presented below are generally net of blanks.

\subsection{Methane production in cultures seeded with anoxic sediment}

For the cultures seeded with anoxic sediments biogas produced in the first 7 days of incubation consisted mainly of carbon dioxide (Fig. 1A). It was not until after 10 days that methane gas was detected in the cultures. The absence of methane production at the early stages of the anaerobic digestion process might be due to initial adaptation of the microbial community of the sediment collected at a temperature of $8^{\circ} \mathrm{C}$ compared to $37^{\circ} \mathrm{C}$ of the digestion process.

As shown in Figure 1A, the results suggest that $L$. digitata was the most digestible substrate and had the highest cumulative methane yield of all the substrates, whilst $F$. serratus produced the lowest cumulative methane gas of the seaweeds tested. The cellulose cultures produced the lowest overall of all the cultures with only $0.052 \mathrm{dm}^{3}$ of methane gas compared to $0.875 \mathrm{dm}^{3}$ produced by L. digitata.

Results of VFA analyses revealed ample volatile fatty acids yield in all experimental cultures, indicative of the effectiveness of hydrolysis and acidogenesis processes. For the anoxic sediment seeded cultures, rapid increase in VFA production was observed in all cultures after Day 8, which reached its peak on Day 23 in all the 3 seaweeds and Day 35 in cellulose cultures as shown in figure 2A. Peak VFA values observed on Day 23 in L. digitata, F. serratus, and S. latissima cultures were $2.514,2.934,4.154{\mathrm{~g} . d m^{-3}}^{-3}$ respectively, while peak VFA value of $1.551 \mathrm{~g} \cdot \mathrm{dm}^{-3}$ in cellulose cultures occurred later on Day 35 as shown in Fig 2A. These results suggest that the sediment inoculum provided effective hydrolytic activity. 

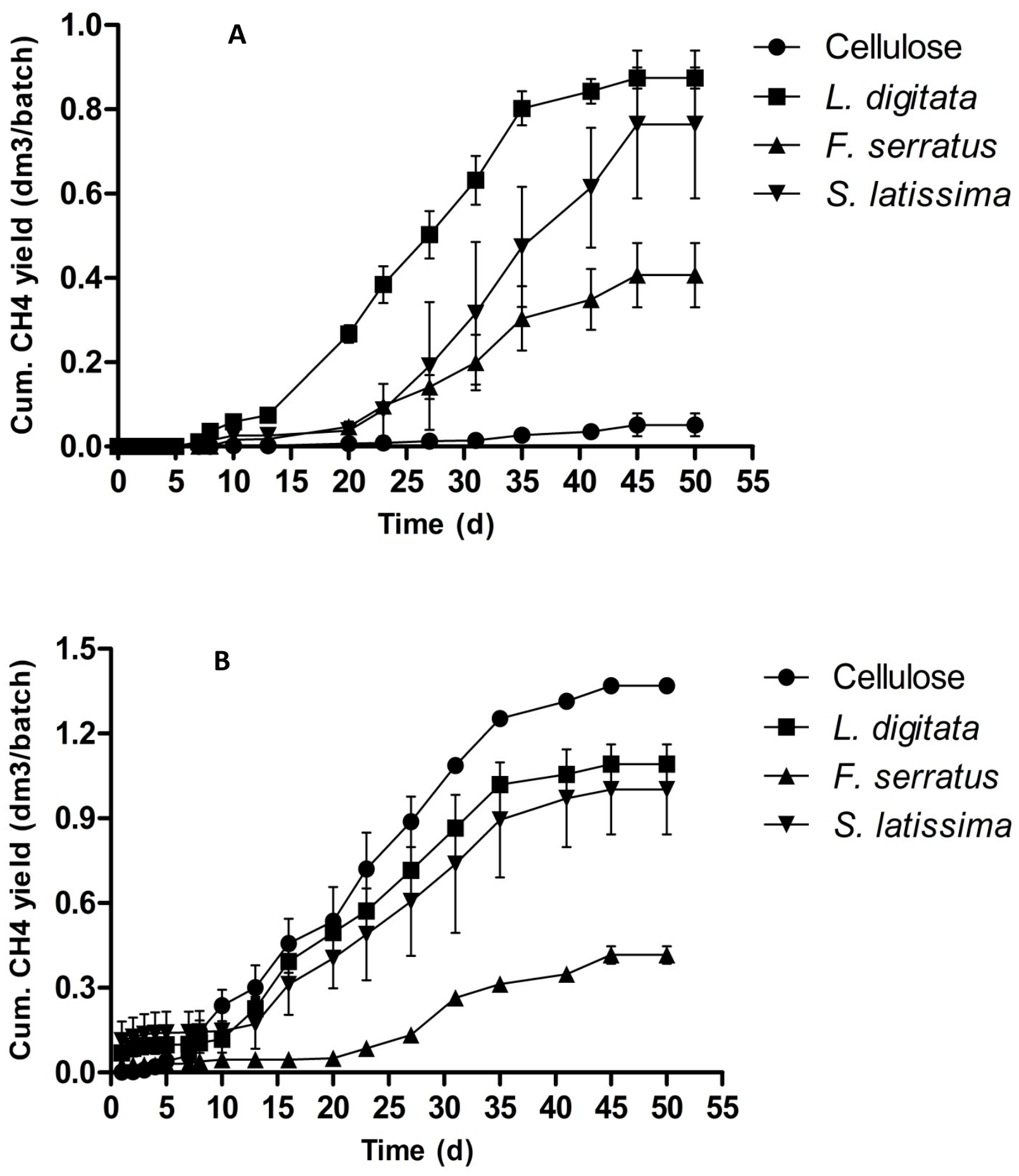

Figure 1. Cumulative methane yield of seaweed cultures seeded with $(A)$ marine sediments and (B) digested sewage sludge. Error bars represent standard deviation from the mean $(n=3)$. 
Moreover, rapid VFAs formation in seaweeds cultures resulted in substantial drops in $\mathrm{pH}$ within the first 48 hours of the AD process. The $\mathrm{pH}$ of all seaweeds cultures dropped below 6.3 from the original 7.5 within the first 24 hours of the test, while the $\mathrm{pH}$ of the cellulose and blank cultures remained steady above 7.2. This may be due to the presence of readily hydrolysable sugars in the seaweeds which could be easily hydrolysed and fermented resulting in faster acid formation and resultant drop in $\mathrm{pH}$ [9]. Moreover, the $\mathrm{pH}$ did not go below 6 in any of the reactors during the hydrolysis and acidogenesis stages, therefore there was no $\mathrm{pH}$ adjustment. The lowest $\mathrm{pH}$ recorded in seaweeds reactors were $6,6.15$, and 6.2 for $F$. serratus, L. digitata and S. lattisima respectively. After the initial drop, a steady rise in $\mathrm{pH}$ was observed in all reactors, despite increasing VFAs production (Fig S1A). This may be as a result of the buffering provided by the buffers included in the experimental set up as well as ammonia accumulation during substrates degradation [31].

Generally, the VFAs produced in sediment-seeded cellulose cultures remained poorly converted during the process. The results demonstrate a preference of the methanogens present in the sediments for seaweeds rather than cellulosic biomass. The methanogens in the marine sediment perhaps require a longer adaptation period in non-marine substrates or were not suited to utilise some of the derivatives of the substrates. More so, the low methane yields obtained from pure cellulose cultures might be due to the lack of cellulase enzyme activity needed to break polysaccharide cellulose into smaller fermentable sugars in the microbial community within the cultures. The results therefore indicate that marine sediments contain microbial populations that are more suited to seaweed digestion than cellulose digestion. Cumulative methane yield of sediment-seeded substrates used in the study is of the order: L. digitata> S. latissima $>F$. serratus $>$ cellulose. 


\subsection{Methane production in cultures seeded with digested sludge}

Methane production started gradually in most sludge-seeded cultures from Day 1 as shown in Figure 1B.This relative greater initial surge of biogas production is believed to be due to abundance of methanogens that are tolerant to a wide range of environmental conditions in the anaerobic sludge and already adapted to mesophilic anaerobic conditions.

Methane production yields in L. digitata and S. latissima seaweed cultures were similar and significantly greater than the yield from the $F$. serratus cultures (Fig.1B), likely because of lower sugar and higher ash content of $F$. serratus [33]. It is also noteworthy that $F$. serratus cultures gave lower methane yields than the other seaweeds in the study in both anoxic sediments and digested sludge seeded cultures (Fig. 1).

Unlike sediment-seeded cultures, sludge-seeded cellulose cultures gave greater methane yields (Fig.1B). This was somewhat expected since the digested sludge is often exposed to cellulose-like substrates, and might contain microbial community that are well adapted to cellulose utilisation. The cellulose culture produced significantly $(p<0.05)$ higher methane yield than $L$. digitata and over 3 times more than $F$. serratus as shown in Figure 1B. Meanwhile, methane yield from the sludge-seeded cellulose cultures was more than 26 times higher than those seeded with anoxic sediment. This is an indication of the suitability of digested sludge over anoxic sediment for cellulose anaerobic digestion. Cumulative methane yield recorded for cellulose and the three seaweed cultures seeded with digested sludge occurred were in the order: cellulose $>L$. digitata> S. latissima>F. serratus.

To examine the likely causes of the observed methane production pattern by the sludge and sediment seeded cultures, the volatile fatty acids (VFA) concentrations of the 
cultures were analysed during the course of the experiment. Results showed differences in the VFA yields by both sets of cultures.

As in the sediment seeded cultures, rapid increases in VFA concentrations were recorded after Day 8 in the digested sludge seeded cultures. However, the levels of their accumulations were lower, perhaps as a result of concomitant conversion by the methanogens into methane. Peak VFA values observed on Day 23 in L. digitata and S. latissima cultures were $2.34,2.66 \mathrm{~g} . \mathrm{dm}^{-3}$ respectively, while peak VFA value of 2.48 and $1.33 \mathrm{~g} . \mathrm{dm}^{-3}$ in F. serratus and cellulose cultures occurred later on Day 27 as shown in Fig 2A.

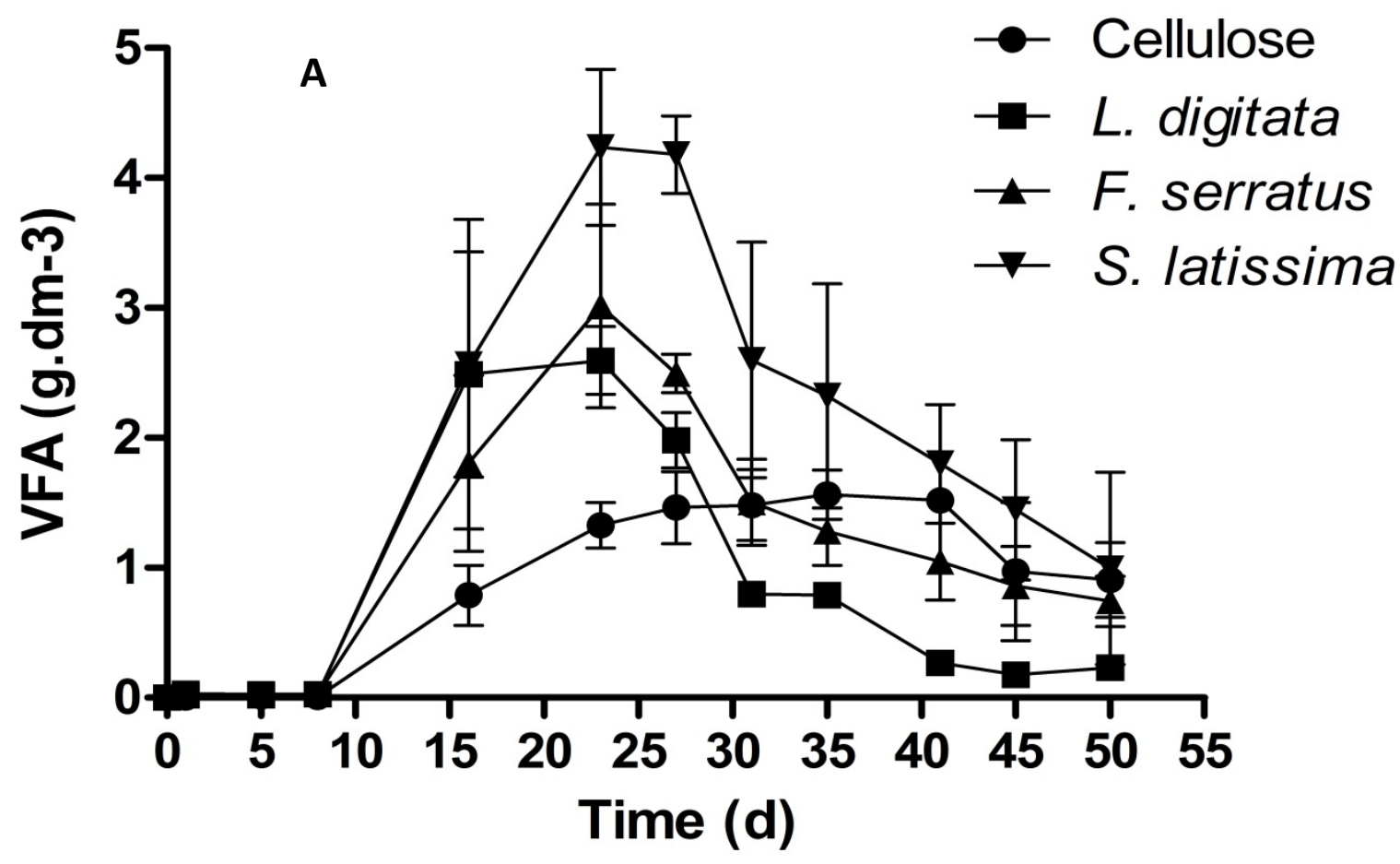




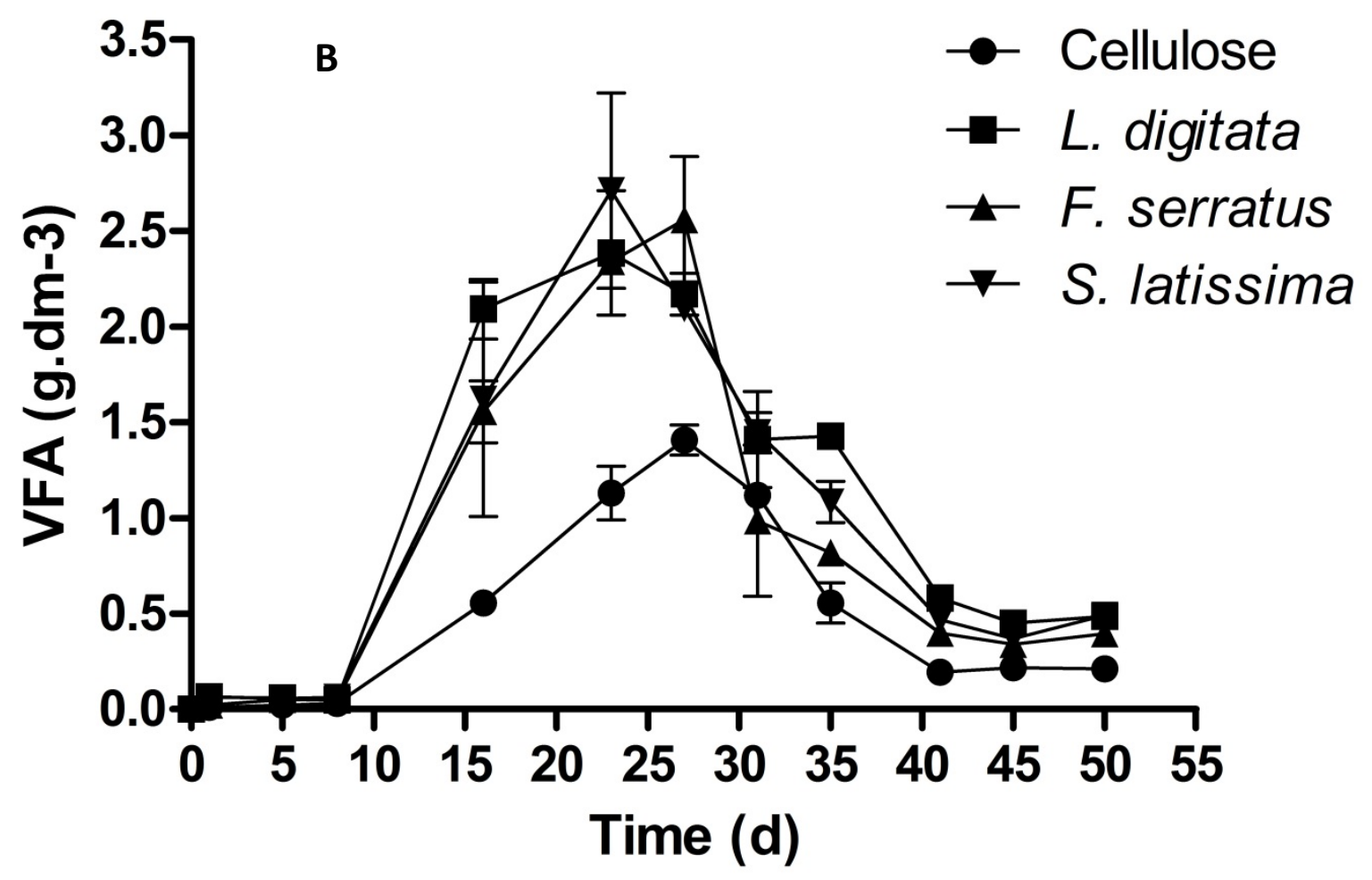

Figure 2. VFA production from experimental samples seeded with (A) marine sediments and (B) digested sludge. Mean VFAs produced by the blank batches was subtracted from the mean of the other cultures. Error bars represent standard deviation from the mean $(n=3)$.

Increases in VFAs concentration resulted in corresponding decline in $\mathrm{pH}$ from the initial 7.5 to $5.3,5.4$ and 6.7 in L. digitata, S. latissima, F. serratus cultures respectively, while the $\mathrm{pH}$ of the cellulose cultures was stable above 7.0 (Fig S1B), perhaps due to no or low VFA accumulation . pH below 6 were re-adjusted within the first few days to avoid inhibition after which a pH stability above 6.5 was established. The VFA concentrations at the end of the experiment were relatively lower than those of the sediment-seeded cultures as shown in Figure 2B,an indication of more effective methanogenic activities in these set of cultures. Moreover, as in the sediment cultures, hydrolysis and acidogenesis were not the limiting steps in the study.

\subsection{Effect of sources of seed inoculum on methane yield}

The specific methane yield for cultures seeded with anoxic sediment were 205, 175, 100 and $10.4 \mathrm{dm}^{3} \mathrm{~kg}^{-1} \mathrm{VS}$ added, for L. digitata,S. latissima, F. serratus and cellulose 
respectively, whilst for cultures seeded with digested sludge, the yields were respectively 256, 230, 103 and $270 \mathrm{dm}^{3} \mathrm{~kg}^{-1} \mathrm{VS}_{\text {added }}$ as shown in Figures 3.

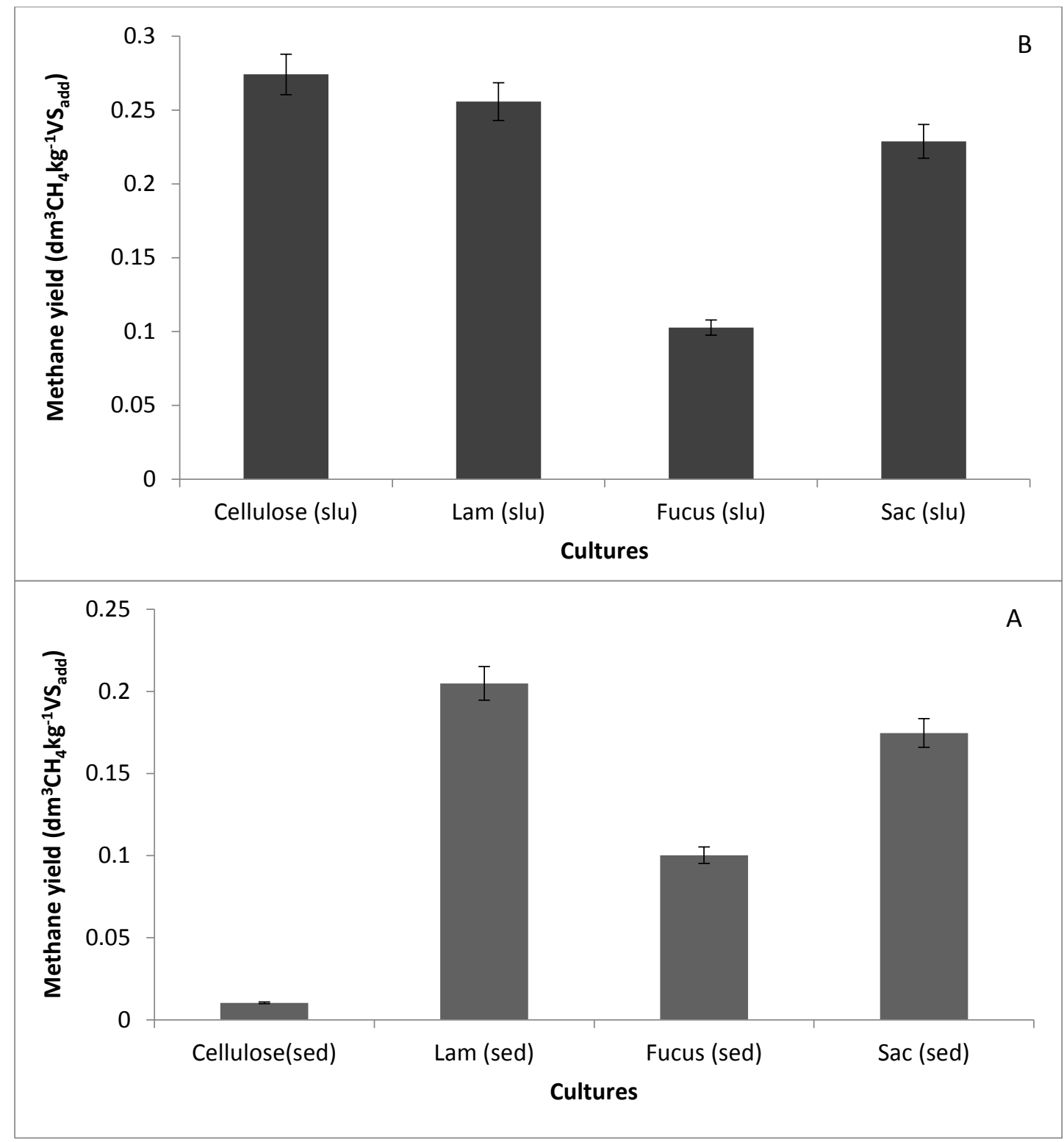

Figure 3. Specific methane yield of seaweed cultures seeded with $(A)$ marine sediments $(B)$ digested sewage sludge. Error bars represent standard deviation from the mean $(n=3)$.

Statistical analysis of the results obtained with the digested sludge inoculum showed that there was no significant difference in methane yield between sludge seeded cellulose and $L$. digitata cultures $(p<0.05)$. Methane yield from $L$. digitata and $S$. latissima in this study compare favourably with those of other substrates reported in the literature as shown in Table 2 . These results therefore suggest that $L$. digitata and $S$. 
latissima are suitable for commercial scale biogas plant. On the other hand, F. serratus seems to be generally poorly biodegradable in anaerobic conditions, as also reported by other authors [32] due probably to relatively high content of recalcitrant and inhibitory compounds such as polyphenols. Although inhibitory polyphenols are present in most brown seaweeds, their concentration in Fucus sp. has been reported to be up to $14 \%$ of the total solids, which is significantly higher than the $2 \%$ in Laminaria and Saccharina spp. [20,33].

Table 2 here

Results of the current study highlight the importance of prior microbial biomass adaptation in the anaerobic digestion process (as shown with marine sediment at mesophilic conditions). Adaptation period can vary from a few days to months depending on the source of inoculum and type of biomass. It is therefore important that future studies are carried out to determine suitable loading conditions before a novel biomass is introduced into an operational anaerobic digestion system to avoid process failure. This is particularly important when marine biomass, by virtue of their seasonal availability fluctuations, is used as sole or part of the feedstock mix in co-digestion systems.

\subsection{Methanogen community in seaweed cultures}

In order to assess the composition of the methanogenic community, clone libraries of the mcrA methanogenic functional genes were constructed from both sludge and sediment seeded cultures. Day 20 Laminaria digitata culture was chosen based on methane production data. 


\subsubsection{Methanogen community in sediment-seeded seaweed cultures}

Results of phylogenetic analysis of 28 randomly selected clones of mcrA gene sequence from sediment seeded cultures reveals sequences affiliated with three orders namely Methanosarcinales (43\%), Methanomicrobiales (43\%) and Methanobacteriales (11\%), while $3 \%$ of the detected methanogens was unclassified. The dominance of Methanosarcinales and Methanomicrobiales in anaerobic digestion processes have been reported previously [34].

All the Methanosarcinales (43\% of methanogens) identified were composed entirely of methanogens related to the genus Methanosarcina. This genus has been reported as the most versatile of all methanogens, because of their ability to utilise the widest range of substrates including acetate, $\mathrm{H}_{2}$ and methyl compounds such as methanol and methylamines. They are also known to be more tolerant to sudden changes in $\mathrm{pH}$ than other methanogens and hence their dominance is indicative of stable and effective process $[35,36]$.

Analysis of methanogens related to the order Methanomicrobiales from the sedimentseeded cultures showed that this order was much more diverse, with at least four genera detected, and Methanofolis being the dominant genus. Others include Methanoculleus Methanogenum, and Methanospirillium. Methanofolis is considered to be a halotolerant hydrogenotrophic methanogens, which is able to metabolise a wide range of substrates such as $\mathrm{H}_{2}+\mathrm{CO}_{2}$, formate, 2-propanol $+\mathrm{CO}_{2}$, 2- butanol $+\mathrm{CO}_{2}$, or cyclopentanol $+\mathrm{CO}_{2}$ but cannot utilise acetate, methanol, ethanol or dimethylamine. It has been detected in a number of habitats such as oil fields [37], fish ponds [38], rumen of buffaloes [39] as well as in anaerobic sludge digesters [26]. Methanoculleus spp. on the other hand, have been reported to be involved in syntrophic oxidation of acetate in digesters containing high concentration of VFAs and compete with acetoclastic 
methanogens for acetate $[27,40,41]$. They also have the ability to metabolise a wide range of substrates such as $\mathrm{H}_{2}+\mathrm{CO}_{2}$, formate, 2-propanol $+\mathrm{CO}_{2}$, or 2- butanol $+\mathrm{CO}_{2}$ for methane production [34,35]. The significant contribution of Methanoculleus spp. to hydrogenotrophic methanogenesis in full-scale anaerobic reactor digesting activated sludge has also been reported $[42,43]$.

\subsubsection{Methanogen community in sludge-seeded seaweed cultures}

Analysis of 28 randomly selected cloned mcrA gene sequences from sludge-seeded cultures revealed sequences affiliated with at least three methanogen orders namely: Methanomicrobiales (39\%), Methanosarcinales (36 \%) and Methanobacteriales (21\%) with about $4 \%$ unclassified methanogens. These results corroborate previous reports of the dominance of genera Methanomicrobiales and Methanosarcinales in various anaerobic digesters $[44,45]$.

Detailed analyses of the sequences within the Methanomicrobiales order were made up of three genera namely; Methanospirillum (37\%), Methanoculleus (36\%) and Methanogenium (27\%). In addition, the order Methanosarcinales is composed of three possible genera. Meanwhile, Methanosaeta-like sequences, accounted for half $(50 \%)$ of the order, Methanosarcinales in sludge seeded cultures. Methanosaeta is the only genus of methanogen that thrives exclusively on acetate. It is one of the most reported genera of methanogens, occurring in a wide range of habitats [40,46-49]. Interestingly Methanoaeta, which forms the bulk (50\%) of the order Methanosarcinales, was not detected in the sediment-seeded cultures.

The second genus of methanogens related to the order Methanosarcinales; Methanosarcina accounting for $40 \%$.These methanogens have been found to be dominant in anaerobic reactors operating at short retention time [36], abandoned coal 
mines [50], in salt-mesh creek sediment [51] and high salinity cultures digesting brown algae [15]. The third Methanosarcinales-like genus, Methanolobus which constitutes 10 $\%$ of the order is both halophilic and exclusively methylotrophic; metabolising methanol, methylamines and sometimes methyl sulphides [52]. Methanolobus has also been detected in large numbers in mesothermic oil fields [37].

\subsubsection{Impact of the source of inoculum on methanogen distribution}

Many similarities and differences were observed between the methanogenic communities of the two sources of inoculum utilised in this study. Figure 4 shows the distribution of methanogen genera within sediment and sludge seeded seaweed cultures.

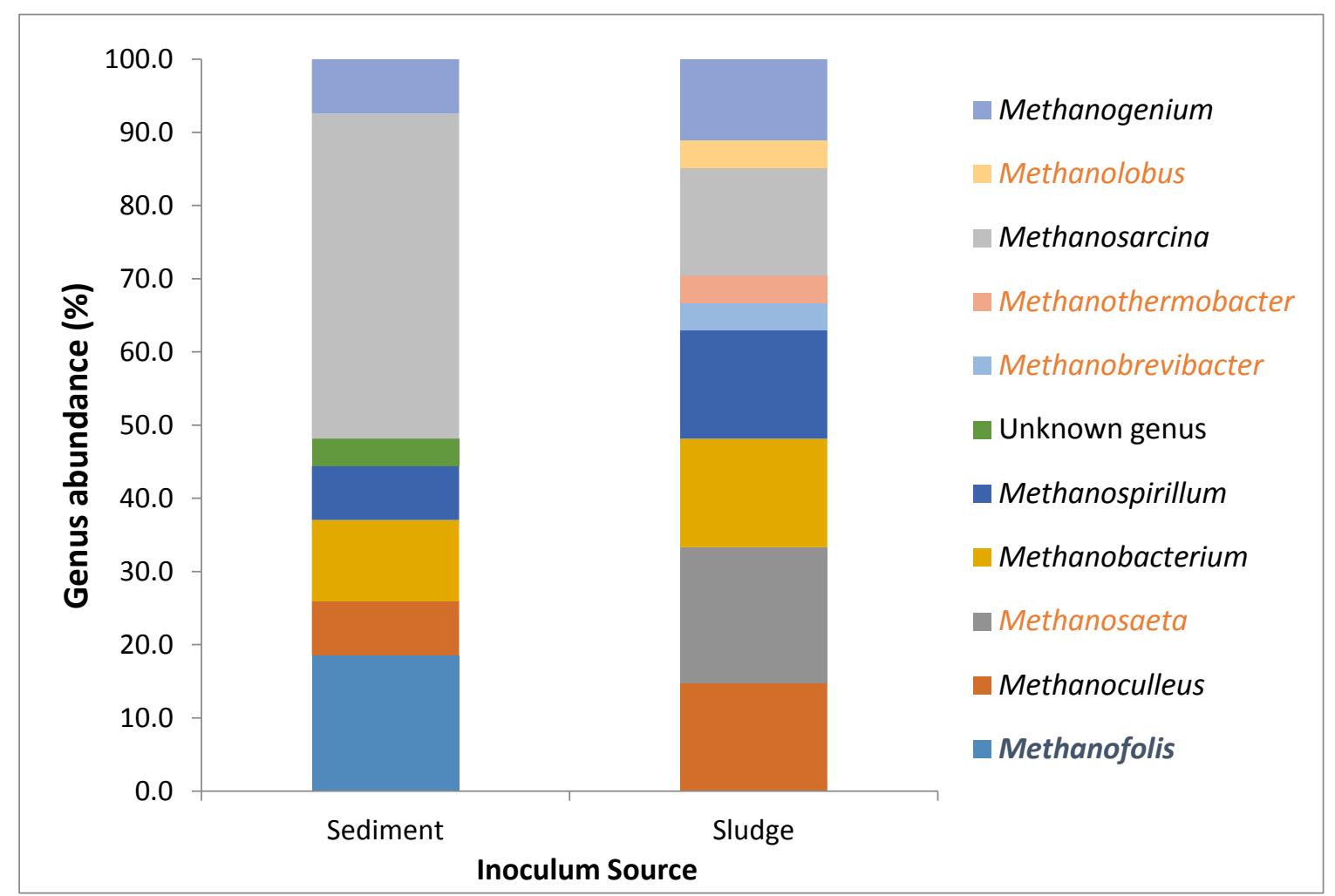

Figure 4. Genus distribution of the methanogen population between marine sediments and digested sewage sludge inoculated cultures. Genus name in blue occurs only in sediment while those in red were detected only in sludge-inoculated cultures. 
At a glance, results showed that the sludge-seeded cultures harboured greater species richness of methanogen sequences with at least 9 sequence types detected, compared to the possible 7 within the sediment seeded ones. The differences in the type and species richness of methanogen sequences might explain the differences recorded in methane yield. For instance, four genera; Methanosaeta, Methanolobus, Methanothermobacter and Methanobrevibacter which were found in the sludge-seeded cultures were not detected in the sediment-seeded cultures. Similarly, Methanofolis which was one of the dominant genera within the sedimentseeded cultures was not detected in the sludge-seeded cultures (Fig 4). It showed that inoculum from wastewater treatment plant provided a more diverse group of methanogens than the sediment inoculum. Incidentally, there is also an absence of Methanosaeta in the sediment inoculum, which are generally considered to be the dominant species involved in acetoclastic methanogensis [50]

Generally, the results of this study suggest that different sources of inoculum introduced different groups of microorganisms into anaerobic digestion reactions. These differences may influence the performance of the system in terms of biogas yield, stability, tolerance to adverse environmental conditions and inhibitory compounds contained in the biomass, e.g. phenolic compounds and salinity associated with seaweed biomass. Therefore, for the co-digestion of seaweeds with other materials such as grasses, food and animal wastes start-up using a mixture of anoxic marine sediments and digested wastewater sludge may provide greater process stability and robustness than if either is used as sole inoculum. This is necessary in order to withstand any adverse effects to the biological process that can be caused by seasonal fluctuations in seaweed availability and hence their loadings to the digester. 
Furthermore, as shown in figures $2 \mathrm{~A}$, a slower conversion of VFA in the sedimentseeded cultures resulted in a bulk of the VFA being unutilised at the end of the study. This observation is supported by the result of the methanogens community analysis, which did not detect any Methanosaeta-like methanogens in these cultures. The absence of Methanosaeta sp. in the marine sediment, which are thought to be responsible for most of the methane production in anaerobic systems $[16,46]$, could explain the build-up of VFA and low methane production recorded. However, Methanosarcinales spp. were detected in the sediment inoculum and these methanogens have been shown to possess the ability to utilise a range of substrates including acetate $[50,52,53]$. As such, the lower methane yields recorded in the sediment-seeded cultures might not be due to the absence of Methanosaeta alone.

\section{Conclusion}

This study highlights that seaweed species such as L. digitata and S. latissima seaweed species are more amenable to biogas production than $F$. serratus under different inoculation conditions. This study showed that methane yield from different reactors was achieved by different types of methanogens. Poor methane yield recorded in the sediment-seeded cultures was as a result of the absence of key methanogenic community needed to convert available volatile fatty acids into methane. Anaerobically digested sewage sludge seemed effective as inoculum for start-up of various substrates including seaweeds.

\section{Acknowledgement}

This work was funded by the European social fund and the Scottish Association of Marine Science, with support from the Scottish Government.

\section{Statement of Informed Consent}

No conflicts, informed consent, or human or animal rights are applicable to this study 


\section{Author Contributions}

Conceptualization: $A H, A D$

Data curation: 00 .

Formal analysis: 00 .

Funding acquisition: $\mathrm{AH}, \mathrm{JA}$.

Investigation: OO, AD.

Methodology: AD, OO, JA.

Project administration: $A H, A D, J A$

Supervision: $A H, A D, J A$.

Validation: $\mathrm{OO}, \mathrm{AH}, \mathrm{AD}, \mathrm{JA}$

Visualization: OO, AD, JA.

Writing - original draft: 00 .

Writing - review \& editing: $\mathrm{OO}, \mathrm{AH}, \mathrm{AD}, \mathrm{JA}$.

\section{References}

[1] A. Singh, S.I. Olsen, A critical review of biochemical conversion, sustainability and life cycle assessment of algal biofuels, Appl. Energy. 88 (2011) 3548-3555. https://doi.org/10.1016/j.apenergy.2010.12.012.

[2] T. Matsui, Y. Koike, Methane fermentation of a mixture of seaweed and milk at a pilot-scale plant, J. Biosci. Bioeng. 110 (2010) 558-563.

https://doi.org/10.1016/j.jbiosc.2010.06.011.

[3] F. Manzano-Agugliaro, a. Alcayde, F.G. Montoya, a. Zapata-Sierra, C. Gil, Scientific production of renewable energies worldwide: An overview, Renew. Sustain. Energy Rev. 18 (2013) 134-143.

https://doi.org/10.1016/j.rser.2012.10.020. 
[4] M. Aresta, A. Dibenedetto, G. Barberio, Utilization of macro-algae for enhanced CO2 fixation and biofuels production: Development of a computing software for an LCA study, Fuel Process. Technol. 86 (2005) 1679-1693. https://doi.org/10.1016/j.fuproc.2005.01.016.

[5] A. Bruhn, J. Dahl, H.B. Nielsen, L. Nikolaisen, M.B. Rasmussen, S. Markager, B. Olesen, C. Arias, P.D. Jensen, Bioenergy potential of Ulva lactuca: Biomass yield, methane production and combustion, Bioresour. Technol. 102 (2011) 25952604. https://doi.org/10.1016/j.biortech.2010.10.010.

[6] J.C. Costa, P.R. Gonçalves, a. Nobre, M.M. Alves, Biomethanation potential of macroalgae Ulva spp. and Gracilaria spp. and in co-digestion with waste activated sludge, Bioresour. Technol. 114 (2012) 320-326. https://doi.org/10.1016/j.biortech.2012.03.011.

[7] A.D. Hughes, M.S. Kelly, K.D. Black, M.S. Stanley, Biogas from Macroalgae: is it time to revisit the idea?, Biotechnol. Biofuels. 5 (2012) 86-93. https://doi.org/10.1186/1754-6834-5-86.

[8] K. Gao, K. McKinley, macroalgae for CO2 remediation.pdf, (1994) 45-60.

[9] N. Wei, J. Quarterman, Y.S. Jin, Marine macroalgae: An untapped resource for producing fuels and chemicals, Trends Biotechnol. 31 (2013) 70-77. https://doi.org/10.1016/j.tibtech.2012.10.009.

[10] V.N. Nkemka, M. Murto, Exploring strategies for seaweed hydrolysis: Effect on methane potential and heavy metal mobilisation, Process Biochem. 47 (2012) 2523-2526. https://doi.org/10.1016/j.procbio.2012.06.022.

[11] A. Khalid, M. Arshad, M. Anjum, T. Mahmood, L. Dawson, The anaerobic digestion of solid organic waste, Waste Manag. 31 (2011) 1737-1744. 
https://doi.org/10.1016/j.wasman.2011.03.021.

[12] F. Raposo, M. a. De La Rubia, V. Fernández-Cegrí, R. Borja, Anaerobic digestion of solid organic substrates in batch mode: An overview relating to methane yields and experimental procedures, Renew. Sustain. Energy Rev. 16 (2012) 861-877. https://doi.org/10.1016/j.rser.2011.09.008.

[13] D.P. Chynoweth, J.M. Owens, R. Legrand, Renewable methane from anaerobic digestion of biomass, Renew. Energy. 22 (2000) 1-8.

https://doi.org/10.1016/S0960-1481(00)00019-7.

[14] H.B. Nielsen, S. Heiske, Anaerobic digestion of macroalgae: Methane potentials, pre-treatment, inhibition and co-digestion, Water Sci. Technol. 64 (2011) 17231729. https://doi.org/10.2166/wst.2011.654.

[15] T. Miura, A. Kita, Y. Okamura, T. Aki, Y. Matsumura, T. Tajima, J. Kato, Y. Nakashimada, Evaluation of marine sediments as microbial sources for methane production from brown algae under high salinity, Bioresour. Technol. 169 (2014) 362-366. https://doi.org/10.1016/j.biortech.2014.07.013.

[16] T. Miura, A. Kita, Y. Okamura, T. Aki, Y. Matsumura, T. Tajima, J. Kato, Y. Nakashimada, Improved methane production from brown algae under high salinity by fed-batch acclimation, Bioresour. Technol. 187 (2015) 275-281. https://doi.org/10.1016/j.biortech.2015.03.142.

[17] O. Obata, J.C. Akunna, G. Walker, Hydrolytic effects of acid and enzymatic pretreatment on the anaerobic biodegradability of Ascophyllum nodosum and Laminaria digitata species of brown seaweed, Biomass and Bioenergy. 80 (2015) 140-146. https://doi.org/10.1016/j.biombioe.2015.05.001.

[18] M.R. Tabassum, A. Xia, J.D. Murphy, Biomethane production from various 
segments of brown seaweed, Energy Convers. Manag. 174 (2018) 855-862. https://doi.org/10.1016/j.enconman.2018.08.084.

[19] J.M.M. Adams, T. a. Toop, I.S. Donnison, J. a. Gallagher, Seasonal variation in Laminaria digitata and its impact on biochemical conversion routes to biofuels, Bioresour. Technol. 102 (2011) 9976-9984.

https://doi.org/10.1016/j.biortech.2011.08.032.

[20] P. Schiener, K.D. Black, M.S. Stanley, D.H. Green, The seasonal variation in the chemical composition of the kelp species Laminaria digitata, Laminaria hyperborea, Saccharina latissima and Alaria esculenta, J. Appl. Phycol. (2014) 363-373. https://doi.org/10.1007/s10811-014-0327-1.

[21] T.L. Hansen, J.E. Schmidt, I. Angelidaki, E. Marca, J.L.C. Jansen, H. Mosbæk, T.H. Christensen, Method for determination of methane potentials of solid organic waste, Waste Manag. 24 (2004) 393-400. https://doi.org/10.1016/j.wasman.2003.09.009.

[22] G. Migliore, C. Alisi, a. R. Sprocati, E. Massi, R. Ciccoli, M. Lenzi, a. Wang, C. Cremisini, Anaerobic digestion of macroalgal biomass and sediments sourced from the Orbetello lagoon, Italy, Biomass and Bioenergy. 42 (2012) 69-77. https://doi.org/10.1016/j.biombioe.2012.03.030.

[23] H.A.. Montgomery, J.F. Dymock, N.. Thom, The Rapid Colorimetric Determination of Organic Acids and their Salts in Sewage-sludge Liquor, Analyst. 87 (1962) 949-955.

[24] L.M. Steinberg, J.M. Regan, Phylogenetic comparison of the methanogenic communities from an acidic, oligotrophic fen and an anaerobic digester treating municipal wastewater sludge, Appl. Environ. Microbiol. 74 (2008) 6663-6671. 
https://doi.org/10.1128/AEM.00553-08.

[25] R. Ciotola, J. Martin, J. Castańo, J. Lee, F. Michel, Microbial Community Response to Seasonal Temperature Variation in a Small-Scale Anaerobic Digester, Energies. 6 (2013) 5182-5199. https://doi.org/10.3390/en6105182.

[26] B.S. Nayak, a. D. Levine, a. Cardoso, V.J. Harwood, Microbial population dynamics in laboratory-scale solid waste bioreactors in the presence or absence of biosolids, J. Appl. Microbiol. 107 (2009) 1330-1339.

https://doi.org/10.1111/j.1365-2672.2009.04319.x.

[27] J. Cardinali-Rezende, R.B. Debarry, L.F.D.B. Colturato, E. V. Carneiro, E. Chartone-Souza, A.M. a Nascimento, Molecular identification and dynamics of microbial communities in reactor treating organic household waste, Appl. Microbiol. Biotechnol. 84 (2009) 777-789. https://doi.org/10.1007/s00253-0092071-z.

[28] G. Rastogi, D.R. Ranade, T.Y. Yeole, M.S. Patole, Y.S. Shouche, Investigation of methanogen population structure in biogas reactor by molecular characterization of methyl-coenzyme M reductase A (mcrA) genes, Bioresour. Technol. 99 (2008) 5317-5326. https://doi.org/10.1016/j.biortech.2007.11.024.

[29] W.R. Pearson, D.J. Lipman, Improved tools for biological sequence comparison., Proc. Natl. Acad. Sci. U. S. A. 85 (1988) 2444-2448. https://doi.org/10.1073/pnas.85.8.2444.

[30] R. Wirth, E. Kovács, G. Maróti, Z. Bagi, G. Rákhely, K.L. Kovács, Characterization of a biogas-producing microbial community by short-read next generation DNA sequencing, Biotechnol. Biofuels. 5 (2012) 41. https://doi.org/10.1186/1754-6834-5-41. 
[31] P. Weiland, Biogas production: Current state and perspectives, Appl. Microbiol. Biotechnol. 85 (2010) 849-860. https://doi.org/10.1007/s00253-009-2246-7.

[32] C.H. Vanegas, J. Bartlett, Green energy from marine algae: biogas production and composition from the anaerobic digestion of Irish seaweed species, Environ. Technol. 34 (2013) 2277-2283. https://doi.org/10.1080/09593330.2013.765922.

[33] M. D’Este, M. Alvarado-Morales, A. Ciofalo, I. Angelidaki, Macroalgae Laminaria digitata and Saccharina latissima as potential biomasses for biogas and total phenolics production. Focusing on seasonal and spatial variations of the algae., Energy \& Fuels. 31 (2017) 7166-7175.

https://doi.org/10.1021/acs.energyfuels.7b00853.

[34] J.-L. Garcia, B. Ollivier, W.B. Whitman, The Order Methanomicrobiales, Prokaryotes. 3 (2006) 208-230. https://doi.org/10.1007/0-387-30743-5_10.

[35] S.K. Cho, W.T. Im, D.H. Kim, M.H. Kim, H.S. Shin, S.E. Oh, Dry anaerobic digestion of food waste under mesophilic conditions: Performance and methanogenic community analysis, Bioresour. Technol. 131 (2013) 210-217. https://doi.org/10.1016/j.biortech.2012.12.100.

[36] J. Ma, B. Zhao, C. Frear, Q. Zhao, L. Yu, X. Li, S. Chen, Methanosarcina domination in anaerobic sequencing batch reactor at short hydraulic retention time, Bioresour. Technol. 137 (2013) 41-50. https://doi.org/10.1016/j.biortech.2013.03.101.

[37] Y. Kryachko, X. Dong, C.W. Sensen, G. Voordouw, Compositions of microbial communities associated with oil and water in a mesothermic oil field, Antonie van Leeuwenhoek, Int. J. Gen. Mol. Microbiol. 101 (2012) 493-506. https://doi.org/10.1007/s10482-011-9658-y. 
[38] N. Banning, F. Brock, J.C. Fry, R.J. Parkes, E.R.C. Hornibrook, A.J. Weightman, Investigation of the methanogen population structure and activity in a brackish lake sediment, Environ. Microbiol. 7 (2005) 947-960. https://doi.org/10.1111/j.1462-2920.2004.00766.x.

[39] R. Franzolin, B. St-Pierre, K. Northwood, A.D.G. Wright, Analysis of Rumen Methanogen Diversity in Water Buffaloes (Bubalus bubalis) Under Three Different Diets, Microb. Ecol. 64 (2012) 131-139. https://doi.org/10.1007/s00248-0120007-0.

[40] A. Dhillon, M. Lever, K.G. Lloyd, D.B. Albert, M.L. Sogin, A. Teske, Methanogen diversity evidenced by molecular characterization of methyl coenzyme $\mathrm{M}$ reductase $A(m c r A)$ genes in hydrothermal sediments of the Guaymas Basin, Appl. Environ. Microbiol. 71 (2005) 4592-4601.

https://doi.org/10.1128/AEM.71.8.4592-4601.2005.

[41] K. Hwang, M. Song, W. Kim, N. Kim, S. Hwang, Effects of prolonged starvation on methanogenic population dynamics in anaerobic digestion of swine wastewater, Bioresour. Technol. 101 (2010) S2-S6. https://doi.org/10.1016/j.biortech.2009.03.070.

[42] J. Guo, Y. Peng, B.-J. Ni, X. Han, L. Fan, Z. Yuan, Dissecting microbial community structure and methane-producing pathways of a full-scale anaerobic reactor digesting activated sludge from wastewater treatment by metagenomic sequencing, Microb. Cell Fact. 14 (2015) 1-11. https://doi.org/10.1186/s12934015-0218-4.

[43] M. Kröber, T. Bekel, N.N. Diaz, A. Goesmann, S. Jaenicke, L. Krause, D. Miller, K.J. Runte, P. Viehöver, A. Pühler, A. Schlüter, Phylogenetic characterization of a 
biogas plant microbial community integrating clone library 16S-rDNA sequences and metagenome sequence data obtained by 454-pyrosequencing, J. Biotechnol. 142 (2009) 38-49. https://doi.org/10.1016/j.jbiotec.2009.02.010.

[44] M. Tabatabaei, R.A. Rahim, N. Abdullah, A.D.G. Wright, Y. Shirai, K. Sakai, A. Sulaiman, M.A. Hassan, Importance of the methanogenic archaea populations in anaerobic wastewater treatments, Process Biochem. 45 (2010) 1214-1225. https://doi.org/10.1016/j.procbio.2010.05.017.

[45] C. Sundberg, W. a. Al-Soud, M. Larsson, E. Alm, S.S. Yekta, B.H. Svensson, S.J. Sørensen, A. Karlsson, 454 Pyrosequencing Analyses of Bacterial and Archaeal Richness in 21 Full-Scale Biogas Digesters, FEMS Microbiol. Ecol. 85 (2013) 612-626. https://doi.org/10.1111/1574-6941.12148.

[46] K.S. Smith, C. Ingram-Smith, Methanosaeta, the forgotten methanogen?, Trends Microbiol. 15 (2007) 150-155. https://doi.org/10.1016/j.tim.2007.02.002.

[47] T. Narihiro, T. Terada, A. Ohashi, J.-H. Wu, W.-T. Liu, N. Araki, Y. Kamagata, K. Nakamura, Y. Sekiguchi, Quantitative detection of culturable methanogenic archaea abundance in anaerobic treatment systems using the sequence-specific rRNA cleavage method., ISME J. 3 (2009) 522-535.

https://doi.org/10.1038/ismej.2009.4.

[48] H. Yu, Q. Wang, Z. Wang, E. Sahinkaya, Y. Li, J. Ma, Z. Wu, Start-up of an anaerobic dynamic membrane digester for waste activated sludge digestion: temporal variations in microbial communities., PLoS One. 9 (2014) e93710. https://doi.org/10.1371/journal.pone.0093710.

[49] A.F. Salvador, A.J. Cavaleiro, D.Z. Sousa, M.M. Alves, M.A. Pereira, Endurance of methanogenic archaea in anaerobic bioreactors treating oleate-based 
wastewater, Appl. Microbiol. Biotechnol. 97 (2013) 2211-2218.

https://doi.org/10.1007/s00253-012-4061-9.

[50] S. Beckmann, T. Lueders, M. Krüger, F. von Netzer, B. Engelen, H. Cypionka, Acetogens and acetoclastic Methanosarcinales govern methane formation in abandoned coal mines, Appl. Environ. Microbiol. 77 (2011) 3749-3756. https://doi.org/10.1128/AEM.02818-10.

[51] R. John Parkes, F. Brock, N. Banning, E.R.C. Hornibrook, E.G. Roussel, A.J. Weightman, J.C. Fry, Changes in methanogenic substrate utilization and communities with depth in a salt-marsh, creek sediment in southern England, Estuar. Coast. Shelf Sci. 96 (2012) 170-178.

https://doi.org/10.1016/j.ecss.2011.10.025.

[52] M.M. Kendall, D.R. Boone, The Order Methanosarcinales, Prokaryotes Vol. 6. (2006) 244-256. https://doi.org/10.1007/0-387-30743-5_12.

[53] M. Klocke, E. Nettmann, I. Bergmann, K. Mundt, K. Souidi, J. Mumme, B. Linke, Characterization of the methanogenic Archaea within two-phase biogas reactor systems operated with plant biomass, Syst. Appl. Microbiol. 31 (2008) 190-205. https://doi.org/10.1016/j.syapm.2008.02.003. 


\section{SUPPLEMENTARY INFORMATION.}

Investigating the impact of inoculum source on anaerobic digestion of various species of marine macroalgae

Oluwatosin Obata ${ }^{a^{*}}$, Arlene Ditchfield ${ }^{a}$ Angela Hatton ${ }^{a}$ and Joseph Akunna ${ }^{b}$ aScottish Association for Marine Science, Dunstaffnage Laboratory, Oban. PA37 1QA, UK.

bUrban Water Technology Centre, School of Science, Engineering and Technology, Abertay University, Bell Street, Dundee DD1 1HG, UK.

*Corresponding author E-mail: oluwatosin.obata@ncl.ac.uk; Tel: +44(0)7528020401.

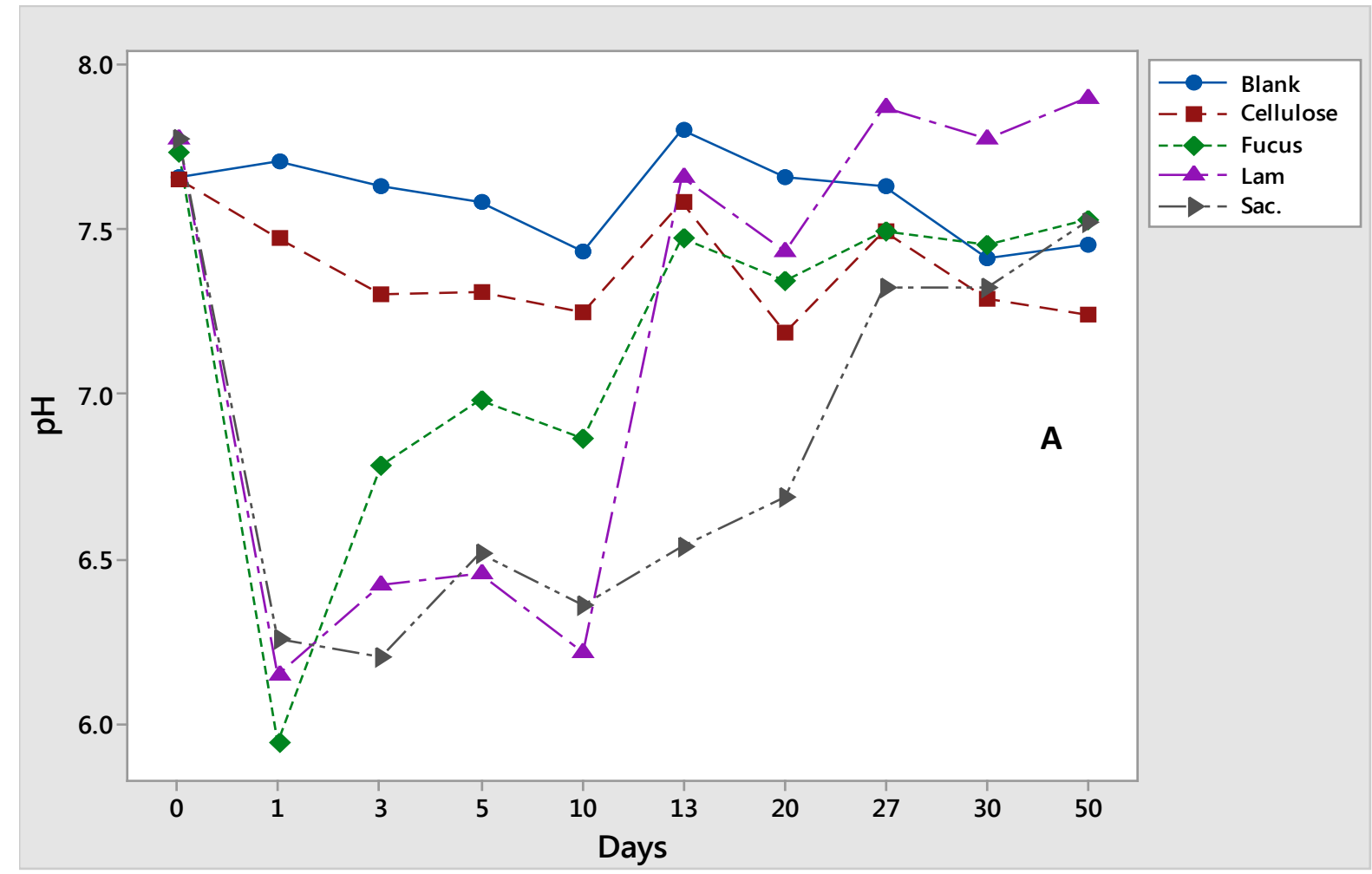

Fig S1A. pH variation in batch reactors during anaerobic digestion of substrates seeded with anoxic sediment. 


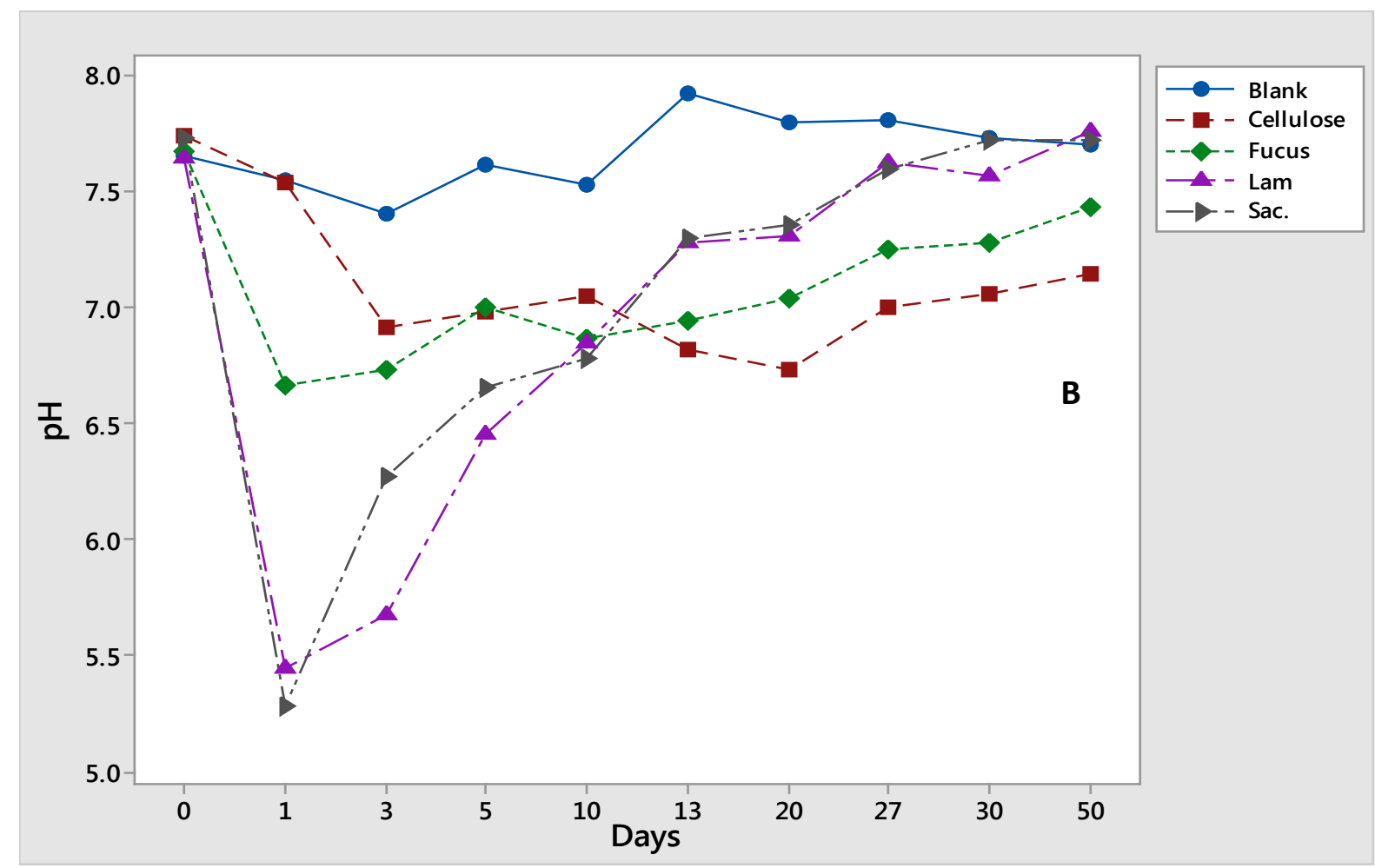

Fig S1B. $\mathrm{pH}$ variation in batch reactors during anaerobic digestion of seaweed substrates seeded with digested sludge. $\mathrm{pH}$ below 6 was readjusted to 7 to avoid system failure. 


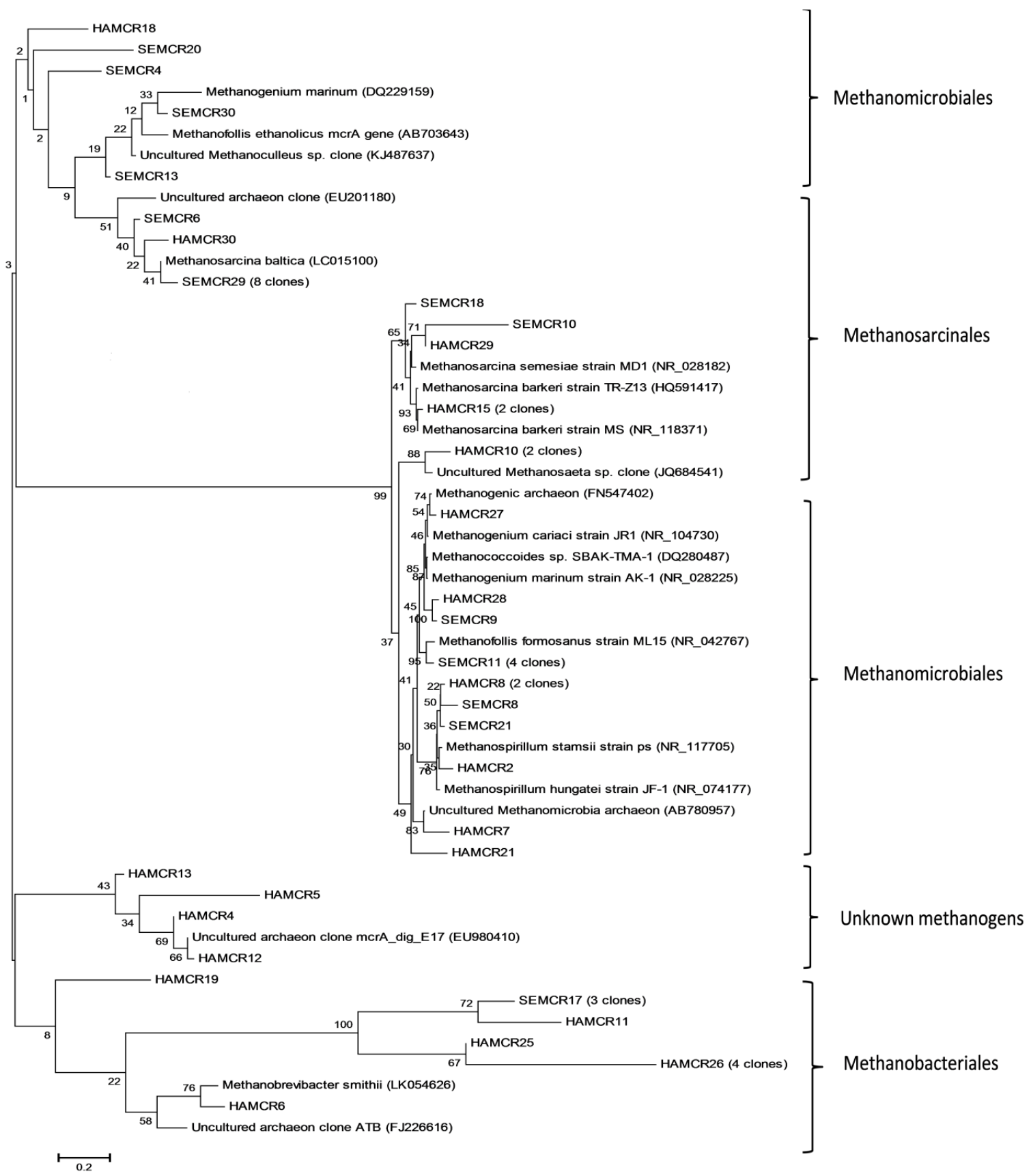

Fig. S2. Phylogenetic tree showing the relationship between representative methanogen clones present in the day 20 sediment (SEMCR) and sludge (HAMCR) inoculated seaweeds reactors and reference organisms (sequences) retrieved from the GenBank database. Accession number of the reference sequences is listed in parenthesis. Phylogenetic tree was inferred using the Neighbour-Joining method. The optimal tree with the sum of branch length $=11.01316005$ is shown. The percentage of replicate trees in which the associated taxa clustered together in the bootstrap test (100 replicates) is shown next to the branches. The tree is drawn to scale, with branch lengths in the same units as those of the evolutionary distances used to infer the phylogenetic tree. The evolutionary distances were computed using the Maximum Composite Likelihood method and are in the units of the number of base substitutions per site. The analysis involved 53 nucleotide sequences. Codon positions included were $1 \mathrm{st}+2 \mathrm{nd}+3 \mathrm{rd}+$ Noncoding. All ambiguous positions were removed for each sequence pair. There were a total of 1845 positions in the final dataset. Evolutionary analyses were conducted in MEGA6. 
